\title{
Improvement of Technological Approaches to the Use of a Combined Method for Eliminating Sinkholes over Mining Workings
}

\author{
Tatiana Tyuleneva ${ }^{1 *}$, and Natalia Khamidullina $^{2}$ \\ ${ }^{1}$ T.F. Gorbachev Kuzbass State Technical University, Department of Management, Accounting and \\ Analysis, 650000 Kemerovo, 28 Vesennya st., Russian Federation \\ ${ }^{2}$ Rostov State University of Railway Engineering, Department of Research, Design and Construction \\ of Railways, 344038 Rostov-on-Don, 2 Rostovskogo Strelkovogo Polka Narodnogo Opolcheniya sq., \\ Russian Federation
}

\begin{abstract}
Analysis of projects for the elimination of open-pit mine workings in Russia has shown that most accidents associated with damage to the earth's surface are caused by critical values of rock pressure in empty spaces, a decrease in the bearing capacity of supports or their absence, as well as loss of stability of support structures. Rapid removal of the generated sinkholes does not always provide positive results, since often the material for filling them is burnt rock, and it was used without studying the properties of the earth's surface, where it is laid. This circumstance leads to the fact that the dips are re-activated. In this regard, the justification of the parameters of the method of eliminating sinkholes is an urgent scientific and practical task. The problem of stability of the abandoned mine workings, as well as geomechanical and environmental safety in the places where they are located, can only be solved using a systematic approach, which involves solving a set of issues to minimize the impact of each factor in the formation of sinkholes both in space and in time. The article describes the approaches to determining the technological parameters of the combined method of eliminating the sinkholes of mine workings, applied taking into account the geological characteristics of rocks and the mining and technical conditions of their location, the use of which will provide a reasonable calculation of the complex of engineering indicators for guaranteed removal.
\end{abstract}

\section{Introduction}

The analysis of projects for the elimination of open-pit mine workings carried out in Russia showed that most accidents associated with damage to the earth's surface are caused by critical values of mountain pressure in empty spaces, a decrease in the bearing capacity of supports or their absence, as well as the loss of stability of support structures. Rapid removal of the formed sinkholes does not always provide positive results, since often the material for filling them is burnt rock without studying the properties of the earth's surface,

\footnotetext{
${ }^{*}$ Corresponding author: kta.bua@kuzstu.ru
} 
where it is laid. This circumstance leads to the fact that the sinkholes are re-activated, especially when flooding. In this regard, the justification of the parameters of the method of eliminating sinkholes is an urgent scientific and practical task.

At present, the problems of geomechanical and hydrodynamic nature that are to be solved in the process of eliminating the consequences of mining sinkholes are well studied, but the regularities of rock deformations during their elimination have not been so carefully studied. An equally important issue in solving problems is also the need to follow regulatory requirements and consciously develop technologies to eliminate sinkholes. To do this, it is necessary to study the conditions for the development of mineral extraction and methods for decommissioning spent mine workings, an in-depth study of the deformation processes of rocks located above the workings, the development of mathematical and physical models of their deformation, as well as the justification of the possibility of using combined methods to eliminate the emergency lowering of the earth's surface.

\section{Theory of Experimental Research}

The mine workings of the eliminated mines after their decommissioning remain unique engineering structures with volumes of up to hundreds of thousands of cubic meters, and therefore their elimination is characterized by increased labor intensity, cost and danger from an engineering point of view. After the decommissioning of the mine workings, all technical measures to maintain them in a stable state are discontinued. The result of this is their permanent destruction under the influence of the decreasing load-bearing capacity of the support materials due to erosion processes, corrosion and the action of other natural, as well as physical and mechanical changes in the fastening material. Most of the dips in the earth's surface are revealed above the collapsing inclined underground workings. This circumstance indicates an insufficient level of development of the technology of elimination of sinkholes of mine workings, enshrined in the legislation, as well as the probability of cavities formation in the material of the filling or the release of the laid rocks to the surface.

The high level of danger of sinkholes of inclined mine workings for natural and anthropogenic landscapes has been repeatedly noted by Russian and foreign scientists [1-6]. The most probable reasons for the occurrence of sinkholes of the earth's surface on the eliminated inclined workings are the cumulative influence of hydrogeological and geomechanical factors, the destruction of the fastening materials of the workings with the formation of sinkhole domes, the instability of the lateral rocks and the collapse of the latter in the direction of the angle of inclination of the workings, the erroneous technological decisions made during the elimination of the workings due to inattention to the mining and mining-geological characteristics of the rocks containing them, incompleteness and poor quality of the filling material in the voids formed by the workings, or even its absence, shrinkage, the degree of which sometimes reaches $50 \%$, and the tendency of the rock filled in as a filling material to seal in the workings over time, the displacement of the filling material from the mine workings into the adjacent voids formed by neighboring workings.

Recovery measures to eliminate sinkholes in mine workings in most cases are based on the use of burnt rock as a material for laying the resulting voids. However, their use for these purposes gives positive results only with such values of physical indicators confirmed by environmental expertise, such as: non - toxicity, voidness, caking, moisture permeability, lumpiness, oxidability, - at which the probability of accidents is minimal. When the burnt rocks, which are prone to moisture permeability and are used as a laying material, are flooded, the so-called undamped creep occurs, which turns into progressive creep, or displacement, which results in the destruction of the laying material used for the structure, with the exposure of the support. Then there is a redistribution of pressure with 
the formation of the dome of the sinkhole, which is manifested by the formation of cracks and craters on the surface of the earth. The destruction of the insulating lintels during the absorption of ground water by the filling material and the displacement of its resulting additional volume into neighboring mine workings can lead to the uncontrolled formation of a terraced, cracked or funnel-shaped dome of the sinkhole.

The maximum height of the sinkhole formation is determined by such factors as the length of the mine workings, the length of the sinkhole zone in the direction of the old workings, the degree of loosening of the collapsing rocks, and the angle of natural inclination. The geometric dimensions of the collapse dome and the amount of deformation of the earth's surface depend on the characteristics of the rock deposits, the hydrogeological regime of the ground water, the strength and deformability of the laying material of the foundation, the rocks in the sinkhole zone, as well as the tendency of the mine workings to form voids in them. The main reasons for the ineffectiveness of using dry filling materials to eliminate sinkholes are large fractions of the dump rocks used for laying; a high degree of their gas and water permeability; incompleteness and unevenness of filling the voids of the compaction of dry material under the influence of attractive forces; a significant value of the shrinkage compression coefficient of the rocks used for laying due to their physical compaction and flooding due to chemical and suffusion hydrological effects. As a result, the possibilities of economic use of the territories are limited; there is a need for structures that restrict access to the eliminated sinkholes, long-term monitoring of sinkholes after the completion of the liquidation work, the threat of re-activation of the displacement of the foundation rocks at the site of the sinkhole; difficulties caused by the financing of regime measures. The watered material involves the use of water in the manufacture of the filling mixture or the transportation of the filling material to the place where the sinkhole is filled. The advantage of its use is the possibility of obtaining the maximum density of the components of the formed filling array, its impermeability to underground water and gases, plasticity, good consistency with the surface of the mouth of the sinkhole. Technological difficulties in applying this method of eliminating dips are caused by large volumes of special equipment and the number of qualified personnel, low density of the laid rock and the degree of permeability of the filling material under the influence of gravity; difficulties in applying the pressure mode of filling the filling solution; high cost-intensity of the work performed. Thus, the experience of using this technology for the formation of a sinkhole filling has demonstrated its inefficiency in eliminating soil sinkholes over mining workings.

Thus, the study of the applied technologies for filling the space of mine workings and eliminating dips above them showed that none of them provides complete moisture resistance, since all the materials used for laying have a significant shrinkage, the degree of which is inversely proportional to the degree of reduction in the filtration coefficient. The use of many methods involves a multi-stage, branched and costly technology of laying and is rarely used in the elimination of mining workings [7-10].

\section{Results and Discussion}

The basis for the creation of a new technology for eliminating sinkholes of the earth's surface with the justification of its design and technological characteristics in order to eliminate the consequences of the impact of coal mine eliminations on the environment based on the use of watered material was the full-scale study of sinkholes over mine workings that open under the influence of the activation of displacement of moisture-filled rocks [11-13]. For the purposes of the study, the sample was carried out taking into account the following conditions: the location of the observed objects on land allotments filled with water-filled filling material; permanent or seasonal increase in the level of underground water at the studied objects by more than 2 meters; selection of land plots that are 
maximally deformed by the mining operations carried out on them. Taking into account the revealed trends in the deformation of the earth's surface under the influence of the displacement of rocks, areas with different degrees of destruction were identified for further research. To form data on the prerequisites for the formation and development of sinkholes over inclined mine workings, studies of the geometric characteristics of the collapses were performed. All the surveyed mine workings with sinkholes formed above them at the time of the start of complex technological measures to close the mines had an unsatisfactory and even emergency technical condition. According to the results of field studies, the main reasons for the activation of sinkhole formation processes are the geological characteristics of the host rocks and the mining characteristics of the workings located in them. On the basis of the obtained data, the analysis of the mining conditions of inclined mine workings was further performed (Table 1).

Table 1. Results of the analysis of mining conditions of inclined mine workings [13]

\begin{tabular}{|l|l|c|l|}
\hline $\begin{array}{l}\text { Condition } \\
\text { assessment }\end{array}$ & Characteristics & $\begin{array}{l}\text { Number of } \\
\text { workings }\end{array}$ & $\begin{array}{l}\text { Probability of } \\
\text { sinkholes }\end{array}$ \\
\hline Good & $\begin{array}{l}\text { Fixed mining with the absence of } \\
\text { deformed roof and 100\% filling }\end{array}$ & 2 & Low (up to 20\%) \\
\hline Acceptable & $\begin{array}{l}\text { Broken fastening of the mine } \\
\text { workings with the absence of } \\
\text { deformed roof and 100\% filling }\end{array}$ & 6 & $\begin{array}{l}\text { Medium (up to 50 } \\
\text { \%) }\end{array}$ \\
\hline Unacceptable & $\begin{array}{l}\text { Mining with no roof attachment and } \\
\text { domes of sinkholes and partial filling } \\
\text { with watered filling material and the } \\
\text { probability of flooding }\end{array}$ & 18 & High (up to 80 \%) \\
\hline Emergency & $\begin{array}{l}\text { Mining with the lack of roof } \\
\text { attachment and multiple domes of } \\
\text { sinkholes, the lack of laying material } \\
\text { and flooding of the workings }\end{array}$ & 34 & $\begin{array}{l}\text { Absolute (up to 100 } \\
\%)\end{array}$ \\
\hline
\end{tabular}

The main provisions of the principal approach to planning the technological characteristics of the combined method of eliminating sinkholes over the mine workings consist in the sequential passage of the elimination stages, their scheme is shown in Fig. 1. 


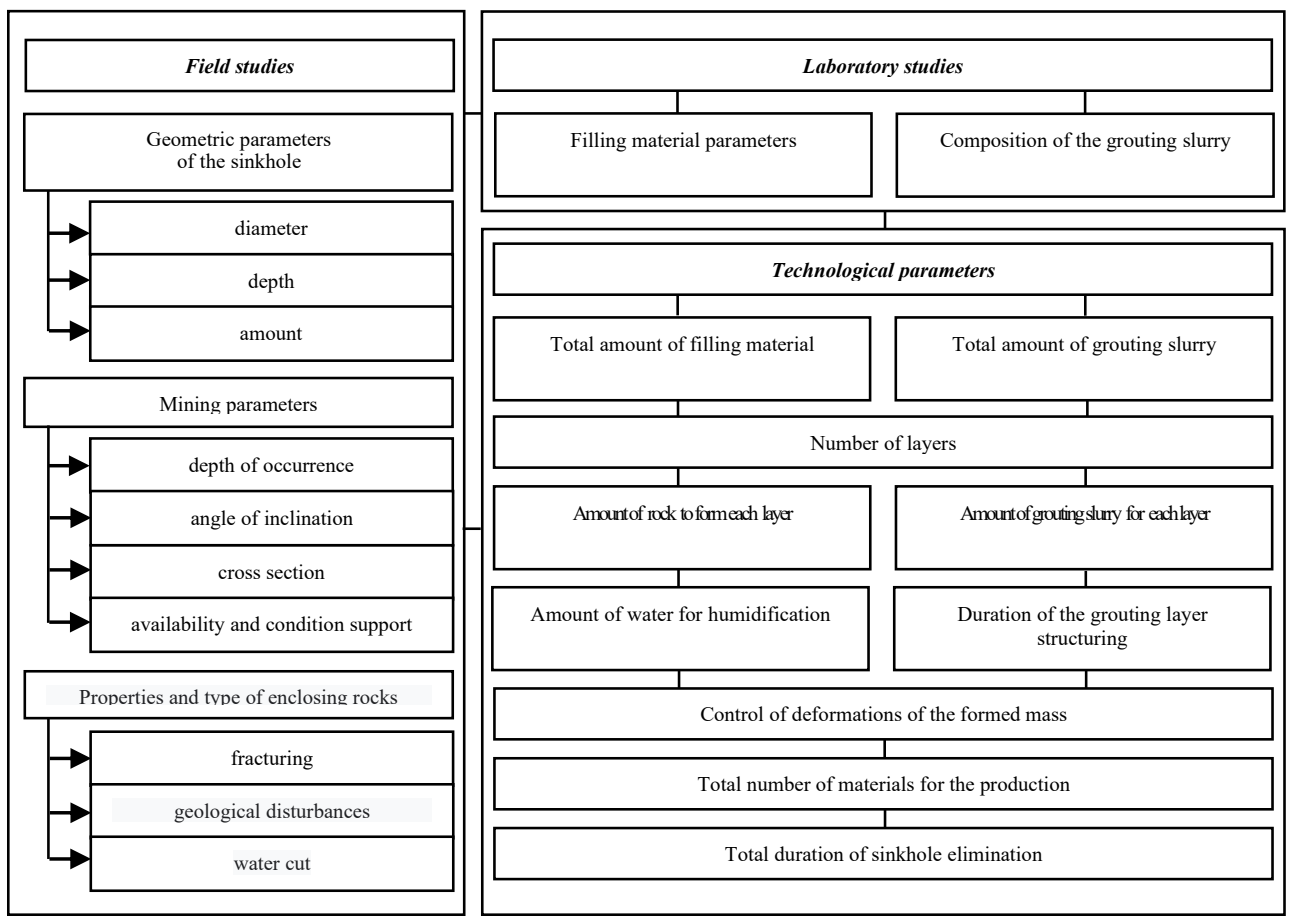

Fig. 1. Generalized method for determining the parameters of the method for eliminating sinkholes of the earth's surface [14]

1. Field studies of collapses and rocks located in the zone of an emergency site with a high probability of sinkhole formation or their presence: formation and processing of geological data on the enclosing rocks of the emergency site; assessment of the strength and deformability of the enclosing rocks; assessment of the degree of violations in enclosing rocks; assessment of the degree of metamorphism of enclosing rocks; assessment of the degree of influence of factors on the formation of sinkholes and its minimization; determination of the parameters of the sinkhole and mathematical modeling of the process of its elimination; formation and processing of data on the extinguished mine workings or the cavities formed underground; assessment of the geometric characteristics of the workings; assessment of the quality of elimination measures in relation to the mine workings under the sinkhole; identification of residual voids in the cross section of the mine workings.

2. The data collected during the first stage is the initial information for evaluating the optimal physical and chemical characteristics of the future filling material and the composition of the grouting suspension for upcoming laboratory studies. Taking into account the mining and geological and strength characteristics of the rocks of the emergency area and the regulatory requirements for similar characteristics of the filling mass, the method of eliminating dips based on a layer-by-layer filling with flooding is used, on the basis of which the technological parameters for each separately developed technology are determined.

3. Evaluation of technological characteristics: determination of the parameters of the filling mass, the basis of the calculations performed is the formation of a non-shrinking mass with a maximum density, which is achieved by using burnt rocks of small fractions; prevention of displacement of burnt rocks of small fractions in the process of water and gas exchange through the use of grouting layers. 
The complex of technological works to eliminate the sinkhole is divided into two stages: preparatory and production [15]. During the preparatory stage at the emergency site, the following activities are carried out: restriction of movement in the area of the sinkhole formation; formation of the site, placement of equipment, design of road traffic flows; development of the rock mass with the preparation of the necessary amount of materials. The production stage of the sinkhole elimination includes the following measures: preparation of the filling mass in the sinkhole zone; prevention of deformation of the filling mass; prevention of displacement of the material of the laying space; grouting of fractured rocks surrounding the sinkhole zone; monitoring the quality of elimination work.

\section{Conclusion}

According to the results of field studies conducted at the eliminated coal mines, it was revealed that with the activation of deformation processes in the laying material and neighboring rocks, there is a decrease in the stability of the adjacent sand-clay massif and the formation of sinkholes. This conclusion became the basis for assessing their geometric parameters and the period of sinkhole formation, but caused difficulties in determining the regularities of this process, since in most of the observations carried out, the fixation of sinkhole formation reflected them as a result of the action of engineering and geological conditions.

In each case, the application of a specific technological scheme to eliminate the sinkhole should be accompanied by a feasibility study of the impact of industrial, mining, geological, environmental and social factors. The scope of application of these technological schemes is determined by the deformation characteristics of the laying mass, the remoteness of the used laying materials, the degree of safety of engineering communications of the existing or eliminated duration, the geographical location of the emergency site. Thus, there is a need for the formation of a structure made of resourcesaving materials, characterized by non-shrinkage and stability, in the place of the sinkhole of the earth's surface above the mining. Based on this, the application of the proposed combined method of eliminating sinkholes consists in the phased implementation of filling works, each of which includes the following stages: filling with material from burnt rocks; watering of the filling material and its subsequent shrinkage to form a grouting-filling slurry; pouring a slurry based on burnt rocks into the space of the sinkhole. Thus, the combined method of eliminating sinkholes involves the formation of a filling mass of layers of compacted burnt rock and a grouting-filling mixture, placed to give the system geomechanical stability and moisture resistance.

The approaches to the application of the combined method of elimination of sinkholes of mine workings, applied taking into account the geological characteristics of rocks and the mining and technical conditions of their location, the use of which will provide a reasonable calculation of the complex of engineering indicators for guaranteed removal, are described.

\section{References}

1. Z. Pan, X. Jiang, M. Lei, Z. Guan, Y. Wu and Y. Gao, Environmental Earth Sciences, 77, 24, 799 (2018)

2. T. Tyuleneva, E3S Web of Conf., 174, 04019 (2020)

3. T. V. Kiseleva, V. G. Mikhailov and G. S. Mikhailov, IOP Conf. Series: Earth and Env. Sci., 84, 012044 (2017)

4. A. Zhang, J. Lu and J.-W. Kim, Geomatics, Natural Hazards and Risk, 9, 1, 211 (2018) 
5. T. Tyuleneva and M. Moldazhanov, E3S Web of Conf., 174, 04061 (2020)

6. V. Mikhailov, V. Karasev and G. Mikhailov, E3S Web of Conf., 41, 02015 (2018)

7. T. Tyuleneva, Proceedings of the 9th China-Russia Symposium "Coal in the 21st Century: Mining, Intelligent Equipment and Environment Protection", 352 (2018)

8. V. Svistun, S. Pakhomov, P. Pigulevskiy and A. Kyrylyuk, International Conference on Geoinformatics, 14 (2015)

9. P. Strzałkowski, Environmental Earth Sciences, 80, 3, 117 (2021)

10. L. Stoeckl, V. Banks, S. Shekhunova and Y. Yakovlev, Journal of Hydrology: Regional Studies, 30, 100701 (2020)

11. A. A. Malinowska and A. Matonóg, Acta Geodynamica et Geomaterialia, 14, 2, 159 (2017)

12. V. A. Voloshin, S. V. Rib, O. A. Petrova and A. V. Belyaev, IOP Conf. Series: Earth and Env. Sci., 012009 (2018)

13. A. Prokopov, S. Stel'Makh, A. Chernil'Nik and M. Prokopova, E3S Web of Conf., 1, 157, 01014 (2019)

14. M. V. Kurlenya and V. A. Skritsky, Journal of Mining Science, 53, 5, 861 (2017)

15. J. J. Royer, J. Litaudon, L. J. Filippov, T. Lyubimova and N. Maximovich, Journal of Physics: Conf. Series, 879, 1, 012018 (2017) 